\title{
Tree or shrub: a functional branch analysis of Jatropha curcas L.
}

\author{
Juliana Tjeuw (i) - Rachmat Mulia • \\ Maja Slingerland $\cdot$ Meine van Noordwijk
}

Received: 16 July 2014 / Accepted: 5 June 2015/Published online: 19 June 2015

(C) The Author(s) 2015. This article is published with open access at Springerlink.com

\begin{abstract}
Jatropha curcas is an oil-bearing semievergreen shrub or small tree with potential as a source of sustainable biofuel, yet information regarding vegetative and fruit biomass in relation to plant architecture is lacking. Research conducted in Indonesia used the tree based functional branch analysis (FBA) model as a non-destructive method to estimate above and belowground biomass, and plant architecture. The FBA utility for shrubs was unknown and required modification. This research used destructive measurements to validate modifications to the FBA model that included sub-
\end{abstract}

Electronic supplementary material The online version of this article (doi:10.1007/s10457-015-9819-5) contains supplementary material, which is available to authorized users.

J. Tjeuw $(\bowtie) \cdot$ M. Slingerland · M. van Noordwijk Plant Production Systems, Wageningen University, P.O. Box 430, 6700 AK Wageningen, The Netherlands e-mail: juliana.tjeuw@wur.nl; julianatjeuw@gmail.com

M. Slingerland

e-mail: maja.slingerland@wur.nl

M. van Noordwijk

e-mail: meine.vannoordwijk@wur.nl;

M.vanNoordwijk@cgiar.org

R. Mulia

World Agroforestry Center (ICRAF), 17A, Nguyen

Khang Street, Yen Hoa Ward, Cau Giay District, Hanoi,

Vietnam

M. van Noordwijk

World Agroforestry Centre (ICRAF),

P.O. Box 161, Bogor 16001, Indonesia categorisation of the tapering coefficient for twig, branch, and wood diameter classes, and addition of a fruit load parameter in the distal link. The modified FBA model confirmed jatropha to be a shrub rather than a tree, producing variable estimates for aboveground biomass. This variation was due to morphological plasticity in the length-diameter relationship of the branches that diverged from fractal branching architecture. Fruit biomass variation between replicates was not well estimated and total proximal root diameter was a poor predictor of total root biomass, due to the proximal roots having enlarged water storage structures that do not follow fractal branching assumptions. Jatropha fruit was shown to predominate on twigs with a diameter between 0.9 and $1.4 \mathrm{~cm}$. Understanding the correlation between fruit development and plant architecture will be necessary for fine-tuning the FBA model for future commercial breeding and selection. The high degree of morphological plasticity displayed by jatropha requires consideration when determining plant biomass.

Keywords Aboveground biomass - Allometry · Belowground biomass · Fractal branching architecture $\cdot$ Proximal root $\cdot$ Stem diameter

\section{Introduction}

Jatropha curcas L. is a semi-evergreen shrub or small tree with oil-rich seeds, belonging to the Euphorbiaceae (Divakara et al. 2010). In Indonesia, there is 
disagreement over whether jatropha is a tree or a crop. Foresters consider jatropha a crop or a plantation crop at best, while agronomists consider it a tree. The disagreement occurs because jatropha has a range of phenotypes; shrub-like, multi-stemmed growth habits with height $<5 \mathrm{~m}$, and tree-like, single-stemmed growth habits with height $>5 \mathrm{~m}$ (Sunil et al. 2013). This problem is not restricted to jatropha as Scheffer et al. (2014) found that $9.2 \%$ of the tree species assessed were classified as shrubs in the TRY (plant traits) database.

Jatropha is of interest for sustainable biofuel production, for socio-economic improvement, and for wasteland reclamation in tropical semiarid regions (Achten et al. 2010; Divakara et al. 2010). Jatropha has been claimed to grow in marginal areas, without competing with food production and is viewed with hopes of providing carbon credits (Divakara et al. 2010; Wani et al. 2012). Many of the envisaged benefits have not materialised. Yields of $12 \mathrm{t} \mathrm{ha}^{-1}$ for example have been claimed and global predictions showed yields of only $5 \mathrm{t} \mathrm{ha}^{-1}$ (Achten et al. 2014). The problem is that expectations were not based on field performance and validated scientific knowledge (Achten et al. 2014; Edrisi et al. 2015). Although uncertainties remain, knowledge gaps are being filled as is evident by the fact that actual measured yields vary from $<0.5-2 \mathrm{t} \mathrm{ha}^{-1}$ (Edrisi et al. 2015). However an understanding of jatropha growth and reproductive biology in combination with breeding for available commercial high yielding planting material, optimum management practices, and suitable growing environment are still lacking (Achten et al. 2014; Edrisi et al. 2015).

To capitalise on the commercial potential of jatropha, basic understanding of plant structure, function, and biomass allocation is required. Biomass and fruit production follow from quantitative relationships between plant size and growth (Niklas 1993). Empirical approaches include relationships between dimensional variables such as tree height and stem diameter, leaf area, weight and volume (Lacointe 2000). Allometric equations can be generated from destructive measurements of tree component biomass as dependent variables with easily measured independent variable such as stem diameter at breast height (MacFarlane et al. 2014).

Plant-based models (PBM) (Vos et al. 2010), functional structural plant models (FSPM) (De Reffye et al. 2009), and functional branch analysis (FBA) or fractal branching models (van Noordwijk and Mulia
2002) have been used to quantify growth and biomass. PBMs view plant growth as a function of factors such as light, temperature, nutrients, water and ambient $\mathrm{CO}_{2}$ and their impact on leaves, stems and roots (Vos et al. 2010). PBMs use defined rules to simulate the physiological process and growth partitions to determine biomass. A limiting factor for PBMs is a lack of feedback between plant growth and plant architecture operating at the phytomer level such as seen in FSPM. In FSPM a phytomer or growing unit (GU) is defined as having one internode, one or more leaves, one or more axillary buds and possibly flowers that form an axis or shoot (De Reffye et al. 2009). FSPM is a virtual plant model based on plant architectural models of Hallé et al. (1978), mathematic models and the Lindenmayer L-system (Prusinkiewicz 2004). FSPM views the plant as a set of phytomers with plant architecture used to integrate environmental responses with feedback between biomass production and biomass partitioning for both development and growth (Vos et al. 2010).

The FBA model (van Noordwijk and Mulia 2002) is a compromise between the PBM and FSPM approaches and uses the "pipe-stem model" theory of fractal geometry of simple tree branching architecture. The pipe model hypothesis is that the crosssectional area (sum of squared diameters) of branches is equal to that of the preceding stem or branch. FBA models produce equation coefficients that relate aboveground tree biomass to the stem diameter at breast height $(\mathrm{DBH})$ or root biomass to proximal root diameter (van Noordwijk et al. 1994). This eliminates, or at least reduces, the need for destructive sampling to determine biomass. The FBA concept has been used to estimate shoot biomass, root length, and root biomass (Smith 2001; Salas et al. 2004), to estimate tree component biomass using standing tree measurements (Santos Martin et al. 2010), and to derive speciesspecific and mixed-species biomass equations (MacFarlane et al. 2014). The model does not predict growth, but provides architectural boundary conditions for transport and support tissues to keep up with leaf and fine root development (Mulia et al. 2010).

Jatropha allometric research historically used empirical models and destructive sampling to determine aboveground biomass (Ghezehei et al. 2009; Achten et al. 2010; Makungwa et al. 2013), with limited belowground data (Firdaus and Husni 2012; Baumert and Khamzina 2015). However, there are no data available for biomass partitioning in the 
generative stage (harvest index). The relationship between inflorescence size, sex ratio, fruit maturation (yield) (Negussie et al. 2014), and plant architecture is important. For instance, in apple and pear trees the reproductive and vegetative branches are different (Costes et al. 2006), while for coffee trees the branches bearing flowers and fruit grow horizontally from the stem (van der Vossen and Herbert 1985; Cilas et al. 2006). In coffee shorter internode length, without a reduction in the numbers of fruit per cluster is also a selection criteria for higher yielding cultivars (Gichimu and Omondi 2010).

FBA has been used to estimate trees biomass but has not been adjusted for shrub architecture. Extension of the plant architectural model to derive potential fruit production has not yet been tested. We therefore set out to test this possibility. The aim of our study was to develop allometric equations for above and belowground jatropha biomass, as grown in Indonesia, using Functional Branch Analysis. Four objectives were: (1) to gain an understanding of the complexity and relationship between jatropha biomass and FBA; (2) to develop improved allometric equations for FBA model in determining above and belowground biomass; (3) to evaluate the FBA model as a nondestructive method for estimating biomass; and (4) to explore whether FBA can be used to identify management practices that increase yield.

\section{Materials and methods}

This study was conducted at a jatropha plantation in Mulo Village in the Wonosari District, Gunungkidul Regency of Special Province Yogyakarta in Indonesia $\left(8^{\circ} 0^{\prime} \mathrm{N}, 110^{\circ} 34^{\prime} \mathrm{E}, 185 \mathrm{~m}\right.$ ASL). A local company, PT. JGE purchased the land and planted jatropha. No agricultural inputs were applied to the monoculture system and local farmers harvested grass on daily basis for cattle feed, while weeding was performed once a month. Planting material was seed propagated from IP$1 \mathrm{M}$, an improved jatropha population of a first selection from Muktiharjo, Central Java (Hasnam and Hartati 2006). Planting density was 2500 plants ha ${ }^{-1}$, spaced $2 \mathrm{~m} \times 2 \mathrm{~m}$ from seedlings transplanted at 3 months.

The region has an equatorial rainforest climate with mean annual rainfall of $1800 \mathrm{~mm}$, mostly occurring from November to April and months with less than $100 \mathrm{~mm}$ per month, mostly in May and October. Mean annual temperature and relative humidity under standard weather station conditions are about $26{ }^{\circ} \mathrm{C}$ and $70 \%$ respectively. The soils are Mollisols with texture varying from clay, silty clay to silty clay loam, with poor drainage. Drainage canals were located around the study site to minimise water logging. The soils are shallow, $10-50 \mathrm{~cm}$ with limestone beneath. Top soil $(0-10 \mathrm{~cm})$ $\mathrm{pH}$ (1: 5) was 7.7 with $\sim 0.9 \%$ organic carbon (Walkley-Black method) and total nitrogen (Kjeldahl method), phosphorus (Olsen method), and potassium (ammonium acetate $\mathrm{pH}$ 7) were $0.5 \mathrm{mg} \mathrm{kg}^{-1}$, $13.8 \mathrm{mg} \mathrm{kg}^{-1}$ and $0.2 \mathrm{cmol}_{(+)} \mathrm{kg}^{-1}$ respectively.

Tree selection

This study used jatropha four-year-old jatropha from monoculture plantings. We selected ten unpruned jatropha in good health, with a single-main stem, and with a minimum of 100 branching points (links). Because of the selection criteria, only four trees with fruit were available which affected fruit biomass estimation. Leaf biomass estimation was not affected as the study was performed before leaf fall commenced. At our site, flowering started at the end of October after a light-rain shower and continued until mid June. Fruit harvesting started in mid to late January and continued through to mid August. Leaf flush started at the end of October after the start of rainy season and reached its peak in mid March, while leaf fall started at the end of June and continued to October. For the selected trees, destructive sampling followed the FBA measurement protocol.

\section{FBA measurements}

FBA aboveground field measurements started in mid April 2012 and finished at the end of May 2012. FBA belowground field measurements followed and were completed in August 2012. FBA details for field measurements are described in the supplementary material. Biomass calculation using the FBA protocol and workbook are available at http://worldagroforest rycentre.org/regions/southeast_asia/resources/wanulc as/3rd-party-tools/FBA.

Destructive measurements

Aboveground destructive measurements were performed after the FBA aboveground measurements 
were completed. Each jatropha was harvested to the base of the stem or until the top of root collar was reached. The aboveground biomass was separated into leaves, fruit, twig, branch, and wood or stem categories. Belowground destructive measurements were performed after roots were excavated and the FBA belowground measurements were completed. Roots were harvested and separated into stump plus tap root, fine roots, proximal roots for twig, branch, and wood categories. All the above and belowground biomass separated categories were subject to fresh and dry weight measurements.

Fresh and dry weight measurements

Fresh weights for each aboveground link category, including leaves and fruit were determined. Dry weights were determined for subsamples to generate a dry weight coefficient. All belowground roots for each of the link categories were weighed. No root washing was required as the soil was friable and only needed gentle rubbing with fingers or picking with forceps. Correction factors were necessary for fresh weight of fine roots and roots with twig category for moisture loss during schematic root drawings and measurements due to the time required from drawing to completing fresh weight measurement. The correction factor was determined from other jatropha roots of similar category measured without any delay after harvesting. Dry weight coefficient for above and belowground subsamples was obtained by drying the samples at $70{ }^{\circ} \mathrm{C}$ until a constant weight was achieved.

\section{Density measurements}

Density measurements for each link category were determined by measuring volume, and wet and dry weights. Volume was measured using single frustum equation (Valdés-Rodríguez et al. 2013). Wet field weights were determined for subsamples of all categories. Dry weights were determined by drying subsamples at $70{ }^{\circ} \mathrm{C}$ to a constant weight and applied to the remaining woody parts (Santos Martin et al. 2010).

\section{Leaf and fine root measurements}

Average leaf area was determined by sampling 100 leaves from each tree. Leaf area was estimated using allometric equation generated by Pompelli et al.
(2012). Specific leaf area (SLA) was determined as leaf area per unit dry weight $\left(\mathrm{cm}^{2} \mathrm{~g}^{-1}\right)$. Leaf dry weight was determined after drying at $70{ }^{\circ} \mathrm{C}$ for $24 \mathrm{~h}$. To determine belowground structure required a full root assessment. Fine roots or feeder roots were determined as having a diameter $<0.1 \mathrm{~cm}$. Specific root length was total root length per dry weight $\left(\mathrm{cm} \mathrm{g}^{-1}\right)$ and determined after drying at $70{ }^{\circ} \mathrm{C}$ for $24 \mathrm{~h}$. Average root length was total root length divided by the number of roots.

Tap root biomass estimation

Belowground biomass estimated from FBA does not include biomass of taproot and roots that grew out from the taproot. An empirical biomass equation to fit regression model estimated taproot biomass (Eq. 1):

$B=a D^{b}$

where $B$ is total biomass and $\mathrm{D}$ is root diameter while (a) and $(b)$ are the constants. The taproot biomass and diameter data were log-transformed prior to regression analysis using least trimmed squares (LTS) to account for heteroscedasticity and potential outliers in the data. Predicted outputs were back-transformed and verified with a correction factor (Ghezehei et al. 2009). Statistical analysis used SAS 9.3 (SAS Institute Inc., Cary, NC, USA).

\section{FBA validation}

Validation of predicted FBA biomass results from biomass of destructive sampling was determined in 1:1 relationship. Because FBA does not use standard fitting techniques, statistical parameters for maximum error (ME), root mean square error (RMSE), coefficient of determination (CD), modelling efficiency (EF), and coefficient of residual mass (CRM) are used (Loague and Green 1991).

\section{Results}

Tree parameters

Tree parameters for aboveground biomass determination were generated from 1754 links and belowground biomass derived from 3182 links from ten trees. 
Table 1 shows tree parameters for above and belowground with similar and contrasting values. Aboveground branching is an almost perfect bifurcation (2.01) with $p$ and $q$ values closest to the pipe model theory, $p=1.01$ and $q=0.66$. The first branching order from the stem shows a sympodial pattern but the next order of branching tends not to be situated opposite each other or following symmetry dichotomous ramification, although it still has a bifurcation of nearly two. Sometimes branches alternate in a herringbone pattern with unequal distances between links, or situated only at one side in an unequal herringbone pattern (Fig. S1).

Average numbers of proximal roots for each tree varied from 7 to 12 with an average diameter of $2.41 \mathrm{~cm}$. This means that proximal roots had double the number of the initial roots. Initially jatropha seedlings propagated from seed show one taproot and four proximal roots that have perpendicular orientation. Over time the initial root structure changes and a more branching structure develops. Mature jatropha also develop 4-8 additional lateral roots that sometimes have oblique roots or lateral roots (sinker roots) that grow vertically similar to the taproot (Reubens et al. 2011).

Compared to aboveground parts, roots had more branches, 2.17 branches at each node and less conservation of cross-sectional area across a branching point $(p=1.71, q=0.76$; see supplementary material Fig. S2). Distribution of $p$ for belowground values were $61 \%$ skewed toward $p>1.25$ that were $38 \%$ from the root diameter category corresponding to aboveground branches, $23 \%$ from the 'twig' root category, and $9 \%$ from the 'woody stem' root category. A high $p$ value indicates that the link cross-sectional area before branching was greater than the sum of the cross-sectional area of links after branching. When added to the fact that one branch had a greater cross sectional area (dominant branch) in comparison with the others ( $q$ value 0.76 ), this indicates a herringbone root branching pattern (van Noordwijk et al. 1994). The herringbone pattern for jatropha root had one main axis (mother branch) that started at the base proximal root and branched to form

Table 1 Average (SD) jatropha main branching parameters for FBA model

\begin{tabular}{|c|c|c|c|c|}
\hline \multirow[t]{2}{*}{ Parameters } & \multicolumn{2}{|c|}{ Aboveground } & \multicolumn{2}{|c|}{ Belowground } \\
\hline & Average & SD & Average & SD \\
\hline Diameter of proximal stem $(\mathrm{cm})$ & 10.22 & 2.21 & n.a & n.a \\
\hline Diameter of middle stem $(\mathrm{cm})$ & 9.36 & 2.23 & n.a & n.a \\
\hline Diameter of distal stem $(\mathrm{cm})$ & 9.03 & 2.03 & n.a & n.a \\
\hline Diameter at $2 \mathrm{~cm}$ aboveground $(\mathrm{cm})$ & 10.10 & 2.23 & n.a & n.a \\
\hline Number of proximal roots of each tree & n.a & n.a & 9.5 & 2.54 \\
\hline Diameter of proximal roots $(\mathrm{cm})$ & n.a & n.a & 2.41 & 1.17 \\
\hline Number of branches & 2.01 & 0.14 & 2.17 & 0.59 \\
\hline$p$ (change in cross sectional area) & 1.01 & 0.61 & 1.71 & 1.2 \\
\hline$q$ (relative allocation to largest offspring) & 0.66 & 0.11 & 0.76 & 0.15 \\
\hline $\begin{array}{l}\text { Twig (D aboveground } \leq 1.99 \mathrm{~cm} ; \\
\text { D belowground }<0.5 \mathrm{~cm} \text { ) length }(\mathrm{cm})\end{array}$ & 16.00 & 14.10 & 16.21 & 17.66 \\
\hline $\begin{array}{l}\text { Branch }(\mathrm{D} \text { aboveground }=2-6.99 \mathrm{~cm} ; \\
\mathrm{D} \text { belowground }=0.5-1.99 \mathrm{~cm}) \text { length }(\mathrm{cm})\end{array}$ & 21.98 & 21.71 & 20.93 & 24.08 \\
\hline Wood (D aboveground $\geq 7 \mathrm{~cm} ; \mathrm{D}$ belowground $\geq 2 \mathrm{~cm}$ ) length $(\mathrm{cm})$ & 11.64 & 10.59 & 10.93 & 11.85 \\
\hline Taper of twig link $\left(\mathrm{cm} \mathrm{cm}^{-1}\right)$ & 0.05 & 0.06 & 0.011 & 0.0006 \\
\hline Taper of branch link $\left(\mathrm{cm} \mathrm{cm}^{-1}\right)$ & 0.03 & 0.1 & 0.023 & 0.029 \\
\hline Taper of wood link $\left(\mathrm{cm} \mathrm{cm}^{-1}\right)$ & 0.10 & 0.25 & 0.085 & 0.14 \\
\hline Twig density $\left(\mathrm{g} \mathrm{cm}^{-3}\right)$ & 0.30 & 0.04 & 0.48 & 0.22 \\
\hline Branch density $\left(\mathrm{g} \mathrm{cm}^{-3}\right)$ & 0.32 & 0.13 & 0.36 & 0.23 \\
\hline Wood density $\left(\mathrm{g} \mathrm{cm}^{-3}\right)$ & 0.34 & 0.02 & 0.26 & 0.12 \\
\hline
\end{tabular}

$S D$ standard deviation, n.a not applicable, $D$ diameter 
smaller, daughter branches with fine roots at only one side, and continued for various lengths before branching into almost two equal size sub branches (dichotomous). The daughter branches maintained a similar iteration as the mother branch. According to van Noordwijk and Purnomosidhi (1995) the distribution of $q$ values in a herringbone pattern shows a gradual decrease in value from 1 to 0.5 , similar to the pattern shown in Fig. S2.

To apply fractal branching model, mean $p$ and $q$ for above and belowground parameters should have independency with the parent diameter as fractal is scale-independent (van Noordwijk and Mulia 2002). Regression analysis shows $R^{2}$ for each parameter is relatively independent and fractal branching model is applicable for jatropha.

The average link length for twig, branch, and wood categories for above and belowground had similar average and standard deviations (Table 1). Average length of twig was $16 \mathrm{~cm}(\mathrm{SD}=14-17 \mathrm{~cm})$, branch was $21-22 \mathrm{~cm}(\mathrm{SD}=21-24 \mathrm{~cm})$ and wood was $11-12 \mathrm{~cm}(\mathrm{SD}=11-12 \mathrm{~cm})$. It seemed for above and belowground link category, increased diameter from twig to branch was followed by increase of length of twig and branch, with the exception of wood category.

Analyses of length and diameter relationship for twig and branch however showed that the relationship was not linear. For this reason, parameterisation of FBA did not use an average value for link length for all categories, but used an average link length for each category. Aboveground final/distal twig links had leaves or leaves and fruit, which means that not all twigs bear fruit. Fruit-bearing twigs were $0.9-1.4 \mathrm{~cm}$ in diameter (Fig. 1) with lengths varying from 4 to $65 \mathrm{~cm}$.

Observations, schematic drawings and data from this study and other pruning and no pruning studies in monoculture, intercropping and hedge systems by Tjeuw et al. (2015) showed that approximately $90 \%$ of fruit produced grew on twigs with a vertical to oblique orientation. Twigs with horizontal orientation, especially if the twig originated from water-sprout branches, produced limited quantities of fruit. The majority of water sprout branches that grew horizontally gave rise to lateral twigs that grew vertically and produced fruit. In addition to the growth orientation of fruit-bearing twigs, branching order pattern did not determine the location of fruit-bearing twig. Fruit-

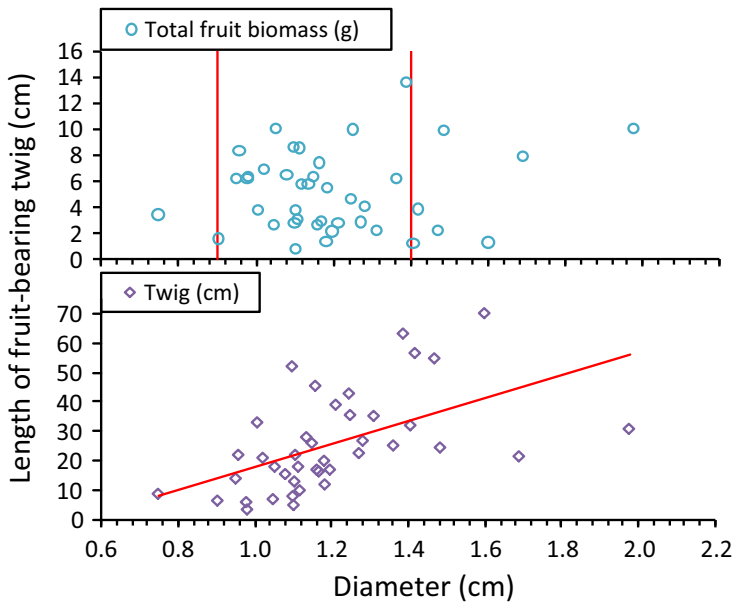

Fig. 1 Relationship between length of fruit-bearing twig with diameter and total fruit biomass; vertical lines in-between fruit biomass show upper and lower limits for diameter boundary determination used for the FBA model; the sloping line relating the length of fruit-bearing twig to diameter indicates a proportionality factor

bearing twigs were found on the first, second, third, and on higher branching order. Furthermore, multiple number of inflorescences or fruit clusters can occur on the same fruit-bearing twig. For instance, once the first inflorescence has developed and set on the young twig, the twig continues to grow or elongate, producing consecutive inflorescences, while the section where the first inflorescence was initiated develops fruit (Tjeuw et al. 2015).

Tapering for above and belowground link of different categories showed a similar pattern with wood having the greatest tapering coefficient compared to branches and twigs, although aboveground wood tapering $(0.1)$ was $18 \%$ greater than belowground wood tapering (0.085). Density for aboveground twig, branch, and wood was around $0.3 \mathrm{~g} \mathrm{~cm}^{-1}$ although wood had the greatest density at $0.34 \mathrm{~g} \mathrm{~cm}^{-1}$. The aboveground density values are very close to the density values determined for 4 month old jatropha seedlings by Achten et al. (2010), $\quad 0.2 \mathrm{~g} \mathrm{~cm}^{-1} \quad(\mathrm{SD}=0.01)$ for stem and $0.26 \mathrm{~g} \mathrm{~cm}^{-1}$ (SD =0.03) for wood parts. On the contrary, density of wood for the belowground category had a lesser density $0.26 \mathrm{~g} \mathrm{~cm}^{-1}$ compared with the branch $\left(0.36 \mathrm{~g} \mathrm{~cm}^{-1}\right)$ and twig $\left(0.48 \mathrm{~g} \mathrm{~cm}^{-1}\right)$. Mujumdar et al. (2000) and Krishnamurthy et al. (2012) found jatropha roots had a well-defined cortex of which large parenchymatous cells arranged 
centripetally that were mostly for water storage and had xylem vessels with assorted sizes, but did not have xylem fibres. The absence of xylem fibres explains the light wood characteristic of jatropha.

\section{Adjustments to the FBA model}

As data showed that a single tapering coefficient was insufficient, three separate tapering coefficients for twig, branch, and wood were introduced. Estimates for fruit biomass were also included, based on distance between fruit on twigs of specified diameter.

\section{FBA output and allometric equations}

Figure 2 shows the predicted increase of above and belowground biomass with increased ratio of proximal root diameter to stem base diameter. The increase in total aboveground weight was much greater than total proximal root weight. For total aboveground weight, branch category made the biggest contribution to total aboveground weight followed by twig and leaf, and finally by fruit. The data serves as the basis for construction of allometric equations (Table 2).

The scaling coefficients derived for total aboveground biomass (2.58) were greater than proximal root biomass (2.12). Twig and leaf biomass scaling was similar to fruit biomass. This is because twigs bear leaves and fruit.

FBA for belowground only simulates proximal root biomass, and not the remaining root biomass such as the taproot and other roots that originate from the taproot. For this reason, the scaling coefficient for the remaining

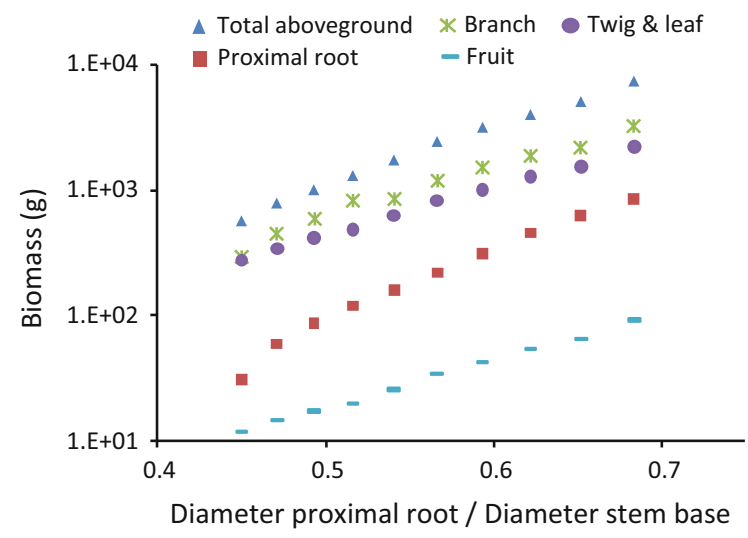

Fig. 2 Relationship of biomass and ratio diameter of proximal root to stem base from FBA output
Table 2 FBA allometric constants and scaling coefficients $\left(B=a D^{b}\right)$ for above and belowground biomass

\begin{tabular}{lll}
\hline FBA scaling coefficients & $a$ & $b$ \\
\hline Aboveground & & \\
Total biomass & 0.0090 & 2.5825 \\
Branch biomass & 0.0088 & 2.2666 \\
Twig \& leaf biomass & 0.0085 & 2.1209 \\
Fruit biomass & 0.0004 & 2.1127 \\
Belowground & & \\
$\quad$ Proximal root biomass & 0.0097 & 2.1870 \\
\hline
\end{tabular}

roots required the use of an empirical allometric power equation with regression analysis. Analysis using least trimmed squares (LTS) regression gave an allometric constant $(a)$ of 0.018 and scaling coefficient $(b)$ of 1.33 $(p>0.0001)$. See Table S1 for details.

\section{FBA validation}

Figure 3 shows a direct comparison around a 1:1 line for FBA predicted and measured values derived from destructive measurements. The FBA model was able to predict total aboveground biomass, branch biomass, and twig and leaf biomass for all jatropha except one. This exception had a much larger basal diameter and was outside the FBA range for the other samples. This outlier was retained within the analysis based on statistical advice as it provides a more realistic representation of the phenotypic or morphological plasticity (heterogeneity) that currently exists with the planting material. Until more uniform planting material can be developed through intensive breeding and selection, the high levels of heterogeneity will require careful statistical consideration. The residuals between measured and predicted (FBA model) for total aboveground jatropha biomass showed significant negative correlation with tree height $\left(R^{2}=0.89\right.$; $p=0.015)$, crown length $\left(R^{2}=0.91 ; p=0.013\right)$ and width $\left(R^{2}=0.89 ; p=0.019\right)$. This resulted in a short crown being predicted as having a massive crown, while a long crown was predicted as having a small crown. Similar to crown length, a narrow crown was predicted as having a wide crown, while a wider crown was predicted as having a narrower crown. FBA for tree height was generated by adding crown length and length of stem/trunk, therefore bias in crown length resulted in bias in tree height as well. 
Fig. 3 Comparison of predicted and measured aboveground tree biomass components: a measured total biomass, $\mathbf{b}$ measured branch biomass, $\mathbf{c}$ measured twig and leaf biomass and for belowground d measured total proximal root biomass
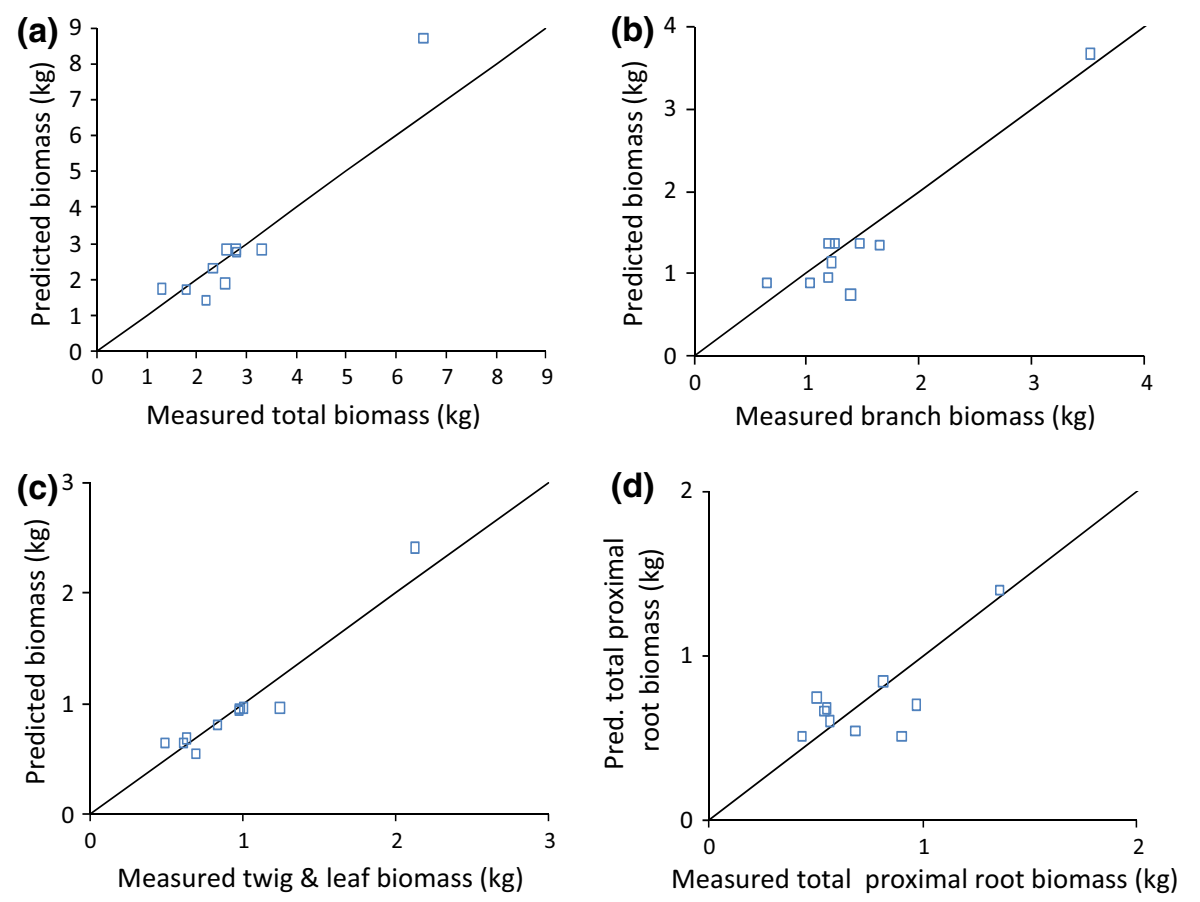

Comparison of predicted and measured belowground biomass shows the model is able to predict total proximal biomass for total proximal root of some trees, but over-estimated small proximal roots in some, and under-estimated large proximal roots in others. Unlike links for the aboveground, the proximal root link for belowground had a different size, shape and length, especially for diameter of branch and wood category links.

Overall, statistical analysis for total aboveground biomass, branch biomass, and twig and leaf biomass indicate the model has an acceptable prediction range and is applicable for biomass estimation (Table 3). Statistical analysis of fruit biomass was not able to confirm viability of the FBA model. Fruit data were limited with only four of the ten trees having fruit. FBA generates fruit biomass based on fruit bearing twig diameter and information relating to this link was limited.

Statistical analysis of total proximal root biomass for belowground showed that the proximal root diameter used in the FBA model only accounts for $56 \%\left(R^{2}=0.56\right)$ of the total proximal root biomass. The remaining percentage was attributable to other, unknown variable(s).
Predictors for aboveground biomass

According to FBA model, above and belowground branching is interconnected and subject to the same rules, therefore stem base diameters relate to root collar diameter and sum of squared diameter proximal roots. Using these independent variables to predict aboveground total biomass of the ten sample trees, the result shows that stem base diameter is the best predictor; followed by square root of sum squared diameter proximal root, root collar diameter and number of proximal root (Fig. 4). RMSE for stem base diameter is 27.9 , square root of sum squared diameter proximal root is 37.5 , root collar diameter is 50.1, and number of proximal root is 56.6. The sum of squared diameter proximal root overestimates aboveground biomass because the diameters include the structures that function as water storage units.

Comparison with other jatropha allometric equations

Empirical allometric equations are available for jatropha biomass from other studies (Table 4). Achten et al. (2010) developed empirical allometric equations 
Table 3 Statistical validation of FBA model for above and belowground biomass estimation

\begin{tabular}{|c|c|c|c|c|c|c|}
\hline \multirow[t]{2}{*}{ Parameter } & \multirow[t]{2}{*}{ Optimum \& range values } & \multicolumn{4}{|c|}{ Aboveground biomass } & \multirow{2}{*}{$\begin{array}{l}\text { Belowground biomass } \\
\text { Total proximal root }\end{array}$} \\
\hline & & Total & Branch & Twig \& leaf & Fruit & \\
\hline $\mathrm{R}^{2}$ & $(1, \geq 0)$ & 0.93 & 0.90 & 0.92 & 0.05 & 0.56 \\
\hline Maximum error (ME) & $(0, \geq 0)$ & 2.16 & 0.64 & 0.29 & 0.04 & 0.39 \\
\hline Root mean square error (RMSE) & $(0, \geq 0)$ & 27.86 & 18.49 & 15.33 & 62.80 & 25.36 \\
\hline Modelling efficiency (EF) & $(1, \leq 1)$ & 0.66 & 0.86 & 0.89 & -0.06 & 0.52 \\
\hline Coefficient of residual mass (CRM) & $(0, \leq 1)$ & -0.03 & 0.06 & 0.003 & 0.19 & 0.02 \\
\hline Coefficient of determination (CD) & $(1, \geq 0)$ & 0.46 & 0.83 & 0.76 & 5.75 & 1.17 \\
\hline
\end{tabular}
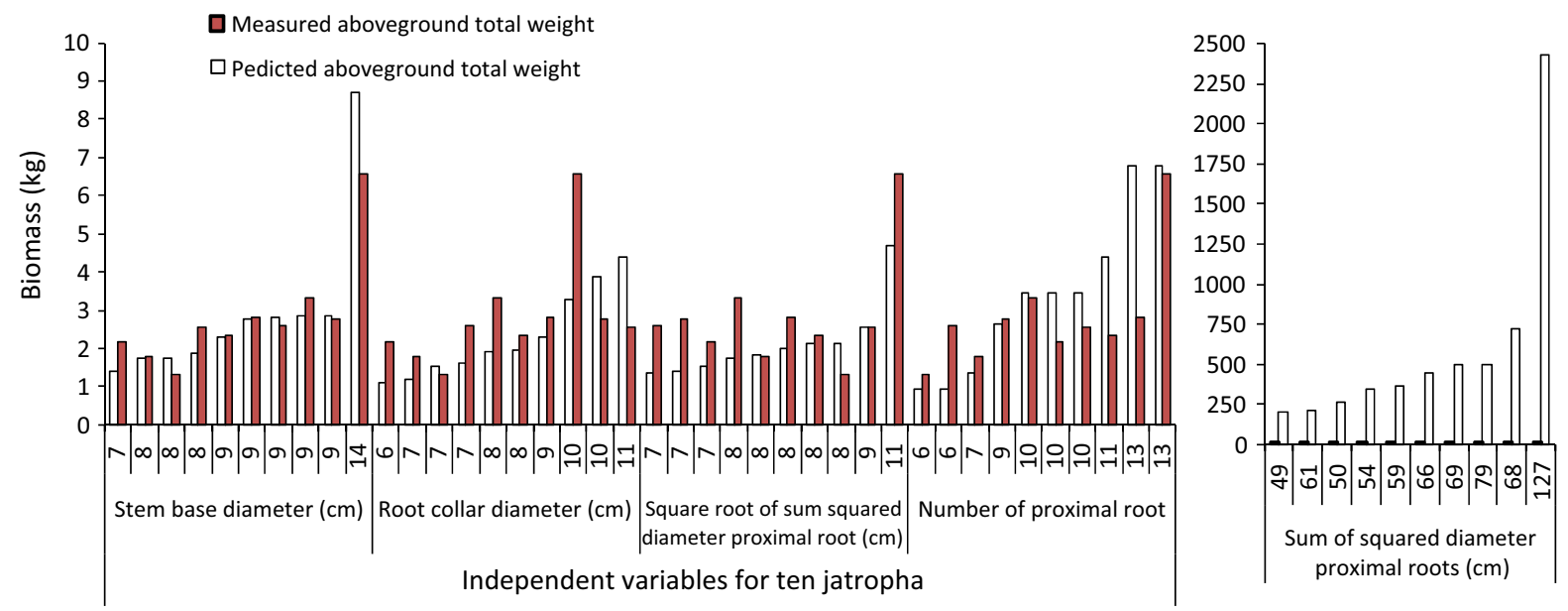

Fig. 4 Biomass of measured and predicted aboveground total weight generated from several independent variables using FBA allometric coefficients in ten trees

using stem diameter to estimate aboveground biomass based on data obtained from 41 jatropha seedlings (up to $3 \mathrm{~cm}$ stem diameter), while Ghezehei et al. (2009) used stem base diameter and other predictors to develop allometric equations for aboveground biomass estimation using 12 samples aged 16-24-monthold. Makungwa et al. (2013) developed two aboveground biomass allometric equations based on stem diameter measured at $10 \mathrm{~cm}$ aboveground from 172 and 442 samples of one to three-year-old jatropha planted as smallholder crop boundary hedges, in five different regions. Firdaus and Husni (2012) determined allometric equations for aboveground and belowground biomass using stem diameter from 15 sampling of 6-46-month-old jatropha. Baumert and Khamzina (2015) developed above and belowground biomass allometric equations using stem diameter measured at $20 \mathrm{~cm}$ from aboveground. The allometric equations were classified as juvenile, adult, and mature based on stem diameter grouping. Data were collected from 141-jatropha plants aged 1-20 years, taken from various production systems.

In Fig. 5 we present the intercept $(a)$ and power coefficient (b) relationships for jatropha allometric equations from six authors, including our jatropha FBA. While the result shows a strong $a$ and $b$ relationship with only one degree of freedom it does not indicate any biological association. It does however suggest that for a particular value of $a$, only a limited range of values for $b$ might be exist, irrespective of any factors (Hairiah et al. 2011). In essence, this allows us to simplify matters and develop one jatropha biomass/diameter allometric equation.

Despite the apparent differences in parameters, a comparison of total aboveground jatropha biomass in relation to stem base or stem diameter showed similar 
Table 4 Jatropha allometric equations from several sources

\begin{tabular}{lccc}
\hline Allometric scaling coefficients & Number of sample & $a$ & $b$ \\
\hline Aboveground & & & \\
Achten et al. (2010) & 41 & 0.029000 & 2.328 \\
Ghezehei et al. (2009) & 12 & 0.000907 & 3.354 \\
Makungwa et al. (2013) 1st equation & 172 & 0.006700 & 2.891 \\
Makungwa et al. (2013) 2nd equation & 442 & 0.005500 & 2.769 \\
Firdaus and Husni (2012) & 15 & 0.002330 & 3.320 \\
Baumert and Khamzina (2015) juvenile stage & & 0.003000 & 2.740 \\
Baumert and Khamzina (2015) adult stage & 141 & 0.003000 & 3.030 \\
Baumert and Khamzina (2015) mature stage & & 0.016000 & 2.310 \\
Belowground & & & \\
Firdaus and Husni (2012) & 15 & 0.000880 & 3.110 \\
Baumert and Khamzina (2015) juvenile stage & & 0.001000 & 2.710 \\
Baumert and Khamzina (2015) adult stage & 141 & 0.001000 & 2.920 \\
Baumert and Khamzina (2015) mature stage & & 0.016000 & 1.880 \\
\hline
\end{tabular}

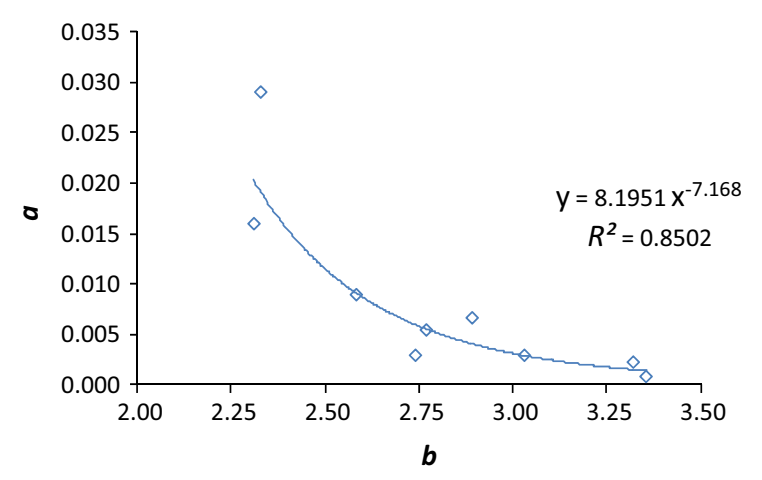

Fig. 5 Relationship of intercept (a) and power coefficient (b) from allometric equations for jatropha from several sources

trends between published sources and the FBA results (Fig. 6). Achten et al. (2010), the first equation of Makungwa et al. (2013) and Firdaus and Husni (2012) share similar patterns with the highest aboveground biomass estimations, whereas Ghezehei et al. (2009) and juvenile stage of Baumert and Khamzina (2015) share the lowest aboveground biomass estimations. The second equation of Makungwa et al. (2013), jatropha FBA, adult and mature stage of Baumert and Khamzina (2015) are situated in the middle of previous two patterns. The grouping pattern for increasing biomass with increasing diameter is likely due to similarities in age. Moreover variations in jatropha biomass across different sources derived from empirical allometric and jatropha FBA can be caused by differences in planting material, site characteristics such as soil, vegetation and over-storey structure (MacFarlane et al. 2014), or in silvicultural practices and development stage or age at the time data were collected (Ghezehei et al. 2009; Makungwa et al. 2013).

As further explored in ongoing research for allometric equations of other species (Harja, pers. comm.), a reformulation of the allometric model to $Y_{x}=\left(\frac{D}{x}\right)^{b}$, with a reference diameter $(x)$ of in this case about $14 \mathrm{~cm}$, can maximise statistical independence of the modified $a\left(Y_{x}\right)$ and the $b$ parameter for all jatropha results (Table 4 plus our study). The FBA result for $Y(14)$ is $15 \%$ lower than the mean of the previous studies.

Ratio below to aboveground biomass

The ratio of belowground to aboveground biomass or root to shoot ratio $(\mathrm{R} / \mathrm{S})$ is a widely used measure to estimate belowground biomass as it is much easier to measure biomass aboveground than belowground. The ratio between belowground to aboveground biomass for this study was determined at 0.5 ; $\mathrm{SD}=0.13$. The aboveground biomass explained $83 \%\left(R^{2}=0.83\right)$ of the variation in the belowground biomass (Fig. 7).

The majority of the below to aboveground ratios were concentrated at the lower end of the regression line with one outlier located at the opposite end. This is because one tree had a much greater below and aboveground biomass in comparison to the remaining trees. The relationship between above and 


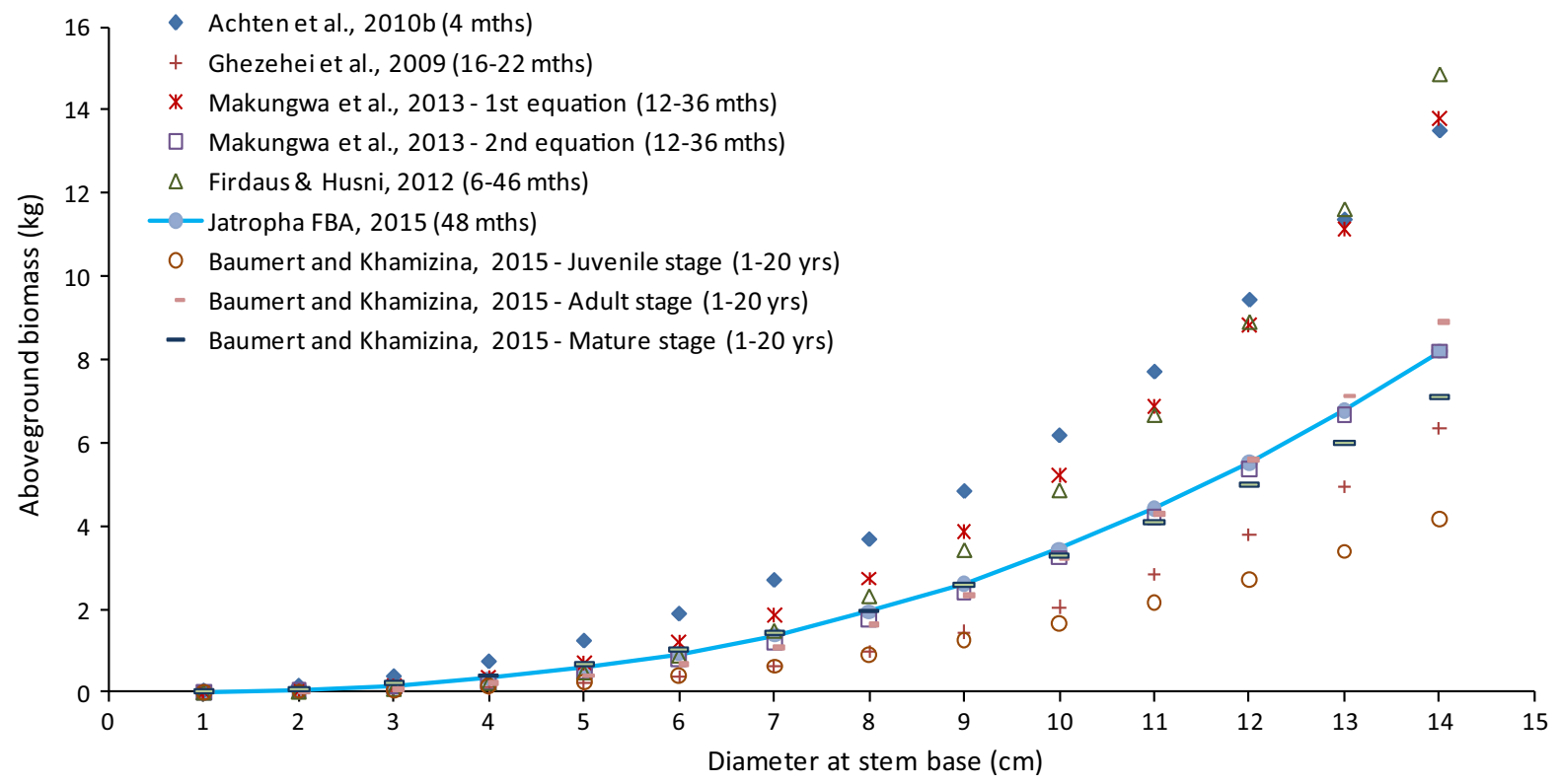

Fig. 6 Relationship of aboveground biomass and diameter at stem base using different jatropha allometric equations from several sources

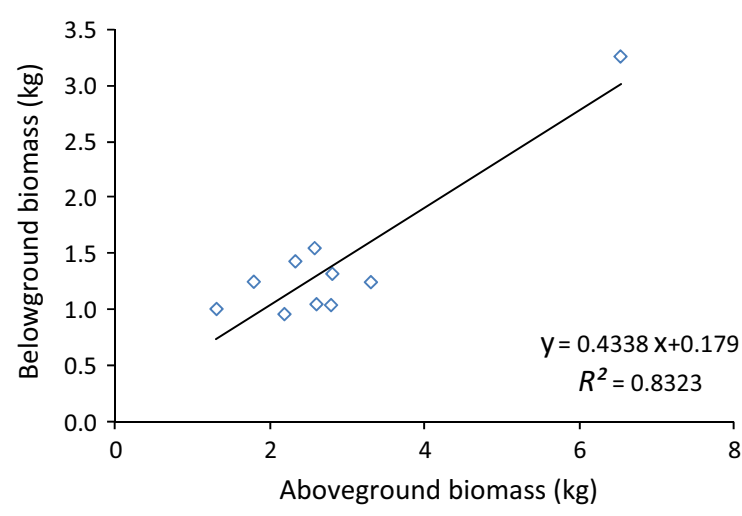

Fig. 7 Relationship between belowground and aboveground biomass

belowground biomass could be explained by the fact that root biomass is essentially the extension of stem underground and branches into taproot and proximal roots, in agreement with the pipe-stem model theory.

Firdaus and Husni (2012) using destructive sampling determined the below to aboveground ratio to be 0.4 for seedlings aged 6-46 months in wasteland areas in Malaysia. Rao et al. (2013) also using destructive sampling, found the below to aboveground ratio to be around 0.3 for jatropha trees aged 8 years in Southern India. Wani et al. (2012) used a below to aboveground ratio of 0.2 to factor the belowground biomass for trees aged 3-5 years in Northern and Southern parts of India. Use of a 0.2 ratio clearly underestimated belowground biomass compared with empirical data. Differences in the below to aboveground ratio results can be due to planting material and tree age, also the agro-ecological conditions of soil, climate and management practises, but also measurement methods, especially for belowground biomass (Mokany et al. 2006; Kuyah et al. 2012).

\section{Discussion}

The FBA model produces both good and poor aboveground biomass estimates of jatropha. This is dependent on how well the jatropha fits the fractal-like allometric scaling dimensions. The poor estimation of aboveground biomass results from inconsistencies in the bias for crown length and width, and tree height estimations. FBA generates crown length by summing the length of links specified by length-diameter relationships. The way link length relates to link diameter is a key relationship in the FBA model calculations. Our data for twig, branch, and wood links did not linearly relate to link diameter and showed a wide variation between trees (Fig. S3), with the exception of twigs bearing fruit (Fig. 1). In the 
absence of such relationship, FBA uses a single value for mean and variance, independent of diameter. Biologically, this relationship is complex as link length is determined by the development and disappearance (self-pruning) of branches, in the axes of (former) leaves. Enhanced development of side branches at the crown surface leads to shortening of link lengths, while shading of the lower branches leads to senescence of side branches (Mäkelä and Valentine 2006) and secondary elongation of links as measured in the FBA protocol. Such trees can be thought of as 'disrupted fractals' where the lengths of links of different diameter branches are somewhat randomised due to historical branch development that effects link length (MacFarlane et al. 2014). This may explain why further statistical approaches using mean link length and measured variability were sufficient to reconstruct measured biomass for some, but were still insufficient to predict biomass for others. Although, this technique provides more structure (predictability) in the location of shorter and longer links in the crown than FBA uses, it cannot fully capture the wide variation between tree links.

Jatropha in this study showed sympodial growth, some with dichasia, and others with multiple branching. The branching pattern follows Leeuwenberg's model (Hallé et al. 1978). Other branching patterns are possible due to the high phenotypic plasticity. Sunil et al. (2013) observed several branching habits and patterns between different germplasm in a monoculture planting at $2 \mathrm{~m} \times$ $2 \mathrm{~m}$, with no pruning, and receiving similar management treatments. Although aboveground phenotypes show a wide range of plasticity, genetic diversity is narrow (Divakara et al. 2010).

The FBA model generates the crown radius allometric coefficients using a vertical projection of the crown leaf area and assuming the shape is uniformly circular. This assumption does not hold for all jatropha so wide crowns may be underestimated while narrow crowns, overestimated. Jatropha grown in a plantation environment may not develop crowns that reach their full potential as they compete within a limited growing space for light, soil nutrient, and water (Mäkelä and Albrektson 1992; Martin et al. 2012). For instance, competition for light between trees may result in shoot or tree crown clumping or self-pruning (Duursma and Mäkelä 2007). Adding to the complexity of competition is the fact that the jatropha used in the FBA calculations showed substantial phenotypic plasticity.
This is despite the fact that the planting material is from one improved population. Future biomass prediction with FBA model may benefit from stratified sampling based on different diameter classes, crown size and shape.

FBA calculates tree height by adding trunk/stem length with fractal crown length. The source of tree height bias for some jatropha came from the crown length bias, as there was no significant correlation between residuals of FBA stem height and measured stem height. Jatropha stem lengths used in this study varied from 2 to $40 \mathrm{~cm}$ from soil surface therefore diameter at breast height (DBH) normally used for developing tree allometric equation was replaced with stem base diameter measured at the middle of the stem length. Moreover, jatropha used in this study was only four-year-old and had stem base diameter ranging from 7 to $14 \mathrm{~cm}$ therefore a reduction in the wood link diameter categorisation to $\geq 7 \mathrm{~cm}$ was required. Consequently, data for wood and main stem parameterisation were identical. The strong tapering found for the main stem did not apply to the branches, therefore the FBA model was adjusted to use separate tapering coefficients for twigs, branches, and wood. The tapering coefficient interacts with the proportionality factor $p$ of cross-sectional area before and after a branching point, in determining the cross-sectional area before the next branching point. When this aboveground structure is considered, jatropha approximates a shrub more than a tree.

FBA for forest trees construct a biomass for the crown wood, branches, twig and leaf, and add the trunk biomass separately as it is subject to other biological and management-related processes. Fractal (self-similarity) properties of the branches are restricted to the crown (Mäkelä 2002; Mäkelä and Valentine 2006). Similar to FBA for forest tree, jatropha biomass was constructed in the same way, with addition of fruit biomass.

The FBA model also using parameters for fruitbearing twigs predicted an allometric scaling coefficient $(b)$ of 2.11 for fruit biomass relative to the stem base diameter. This is in agreement with a value of $<2.2$ for the allometric scaling coefficient for plant reproductive biomass when the stem tapered (Niklas 1993). Although the predicted scaling coefficient for fruit biomass is in agreement with other studies, the fruit data for this study was limited and results for older plants may differ. 
Corner's rule recognises a positive correlation between twig size and leaf, inflorescence, fruit, and seed size (Westoby and Wright 2003; Chen et al. 2010). For fruit-bearing twigs in jatropha, twig length and diameter were correlated; twig diameter was better as predictor of fruit presence than link length, with twig diameters between 0.9 and $1.4 \mathrm{~cm}$ representing $83 \%$ of fruits observed. Chen et al. (2009) studied fruit-bearing twigs across 55 woody species and found that fruit and seed biomass were positively correlated with twig diameter, but negatively correlated with the ratio of twig length to diameter. Chen et al. (2009) also found that twig size was not significantly correlated with seed size, possibly due to the large variation in seed numbers per fruit and a negative relationship between seed size and number of seeds per fruit.

Although the study of fruit-bearing twigs in relation to reproductive biomass is still in the very early stages, this study highlights the importance of architecture, especially when trying to correlate fruit biomass with breeding and management practices. Research into the relationships between length and diameter for links bearing fruit, fruit dimensions, and pericarp to seed ratios is required for improved simulations. It will also be important to investigate the critical switching point for twigs with diameters between 0.9 and $1.4 \mathrm{~cm}$ to understand why some twigs bear inflorescences and others do not. Moreover, fruit-bearing twigs can be located anywhere on the tree regardless of the branching order and often bear multiple inflorescences or fruit clusters (Tjeuw et al. 2015). Contrary to the observations by Ghosh et al. (2011) our results show that branches situated in the lower part of the canopy and shaded by upper branches do flower and produce fruit, although at a reduced level. If light does determine flowering, then there must be a range over which it operates given that inflorescence initiation and fruit set occurs in areas where light is limited. Such a range is likely influenced by resource availability and allocation in combination with twig diameter. This possibility opens up an interesting area of research into flowering physiology in response to twig size and external stimuli such as light quality and/or quantity.

It is important for plant breeders to understand agerelated characteristics to be able to optimise genetic gains per unit of time, rather than waiting for a tree to start producing. An example of this is coffee breeding where yield prediction is possible through architectural development, as coffee only flowers and fruits on lignified plagiotropic (horizontal) branches (Cilas et al. 2006). In coffee, the internode length between inflorescences on plagiotropic branches is an important trait, as it not only determines carbohydrate allocation, but also carbohydrate distribution to inflorescences and fruit. Based on understanding of coffee tree architecture, selective branch pruning, branchwounding (ring-barking) and grafting of productive plagiotropic branches to other trees to increase yields is already standard management practice (Esther and Adomako 2010). Plant architecture has proved commercially beneficial in coffee breeding and may prove useful for future jatropha breeding and management practices.

FBA belowground biomass estimation for total proximal root biomass had a greater bias compared with aboveground biomass. Proximal roots enlarge into structures that store water, a root structure not factored into the FBA pipe model theory. The theory determines that a pipe represents a 'bundle of unit pipes' each of which has a water and nutrient transport function (Mäkelä 1986). The bundles of pipes are interconnected, one to the other where transport capacity is determined by the stem or proximal diameter (van Noordwijk and Purnomosidhi 1995).

FBA belowground biomass estimations do not take into account taproot or stump biomass, as these organs do not follow a fractal model; these organs, however contribute $30 \%$ of total measured belowground biomass in jatropha. For this reason, it is necessary to generate empirical allometric equations for the taproot using its diameter as the predictor variable. The estimated taproot weight can be added to estimated total biomass based on proximal roots as a predictor, to derive total belowground biomass.

Jatropha roots typically are intermediate in branching pattern between a herringbone and dichotomy pattern (van Noordwijk et al. 1994). Herringbone root systems minimise intra-plant root competition so are more effective at resource acquisition, despite their roots being larger, and more resource demanding. Dichotomous root systems have higher intra-plant competition although they are smaller and require less resources (Fitter et al. 1991). It is apparent that jatropha is able to respond to differences in resources availability through root structure modification. 
Implementation of the revised FBA model (with tapering coefficients depending on link diameter classes) for estimating jatropha biomass will be easier and cheaper than relying on destructive methods for further studies. For density measurements a small tree corer could be used to extract a sample, alternatively using previously published density values (MacFarlane et al. 2014). The revised FBA model offers estimations of biomass partitioning for fruit, twig and leaf, and branch, including total biomass. FBA also shows that aboveground fractals are interconnected with belowground fractals, and that root collar diameter and square root of sum squared proximal root diameter can be used to estimate aboveground biomass. The best estimation for aboveground biomass however comes from using stem base diameter.

Below to aboveground ratio is a function of genotype and a reflection of resource allocation and the limitations (stress) imposed within the environment (Taub and Goldberg 1996; Aikio and Markkola 2002). Although not fully understood, above and belowground parts are functionally interdependent and able to maintain a dynamic biomass balance depending on resource availability. In basic terms when light is the predominant limiting factor, resources are allocated to aboveground growth, and when nutrients are the limiting factor, preference is given to belowground growth. Jatropha is a shade intolerant plant therefore a greater proportion of biomass is invested aboveground than belowground. In this study light was probably a limiting factor as canopy closure had already occurred in the four-yearold jatropha planted at $2 \mathrm{~m} \times 2 \mathrm{~m}$. The below to aboveground ratio is an indicator of functional plasticity (Aikio and Markkola 2002) in response to growth-limiting resources. In jatropha the roots act as belowground storage organ as part of overall plastic response (Grams and Andersen 2007).

\section{Conclusions}

From the FBA perspective, Jatropha curcas is categorised as a shrub more than a tree as it does not have a prominent trunk. Implementation of a revised FBA model provides variable estimations of total aboveground biomass for twig, leaf and branch biomass depending on how well the jatropha fit the fractal branching architecture. The strength of this model is its application as a non-destructive technique for determining aboveground biomass. Fruit biomass was not well estimated so further research is required on fruit-bearing twigs and fruit dimensions to fine-tune the model. Proximal roots as a predictor of belowground biomass produced poor results because the cross sectional area of the proximal root do not follow the fractal branching pattern. One possible solution might be to use root diameters farther from the stem as basis for allometric equations. The measured below to aboveground ratio of 0.5 observed in this research was higher than in other jatropha studies. These differences highlight a degree of morphological plasticity that requires consideration when determining plant biomass. Below to aboveground ratio requires referencing against whole plant biomass for meaningful results.

Acknowledgments This study was part of the research cluster for JARAK: 'The commoditisation of an alternative biofuel crop in Indonesia' under Agriculture beyond Food ( $\mathrm{AbF}$ ) program funded by KNAW-NWO (Grant Number W07.55.301.00). We thank PT. JGE for providing the experimental site and planting material during the study. We express our gratitude to students and lecturers from the University of Gadjah Mada in Yogyakarta, in particular the Agronomy Department from the Faculty of Agriculture and the Forest Management Department from Faculty of Forestry for assistance with field and laboratory work during this study. We thank Ken Giller for comments and corrections of this manuscript. We also thank two anonymous reviewers for their detailed and constructive comments.

Open Access This article is distributed under the terms of the Creative Commons Attribution 4.0 International License (http:// creativecommons.org/licenses/by/4.0/), which permits unrestricted use, distribution, and reproduction in any medium, provided you give appropriate credit to the original author(s) and the source, provide a link to the Creative Commons license, and indicate if changes were made.

\section{References}

Achten WMJ, Maes WH, Reubens B, Mathijs E, Singh VP, Verchot L, Muys B (2010) Biomass production and allocation in Jatropha curcas L. seedlings under different levels of drought stress. Biomass Bioenergy 34:667-676

Achten WMJ, Sharma N, Muys B, Mathijs E, Vantomme P (2014) Opportunities and constraints of promoting new tree crops-lessons learned from jatropha. Sustainability 6:3213-3231

Aikio S, Markkola MA (2002) Optimality and phenotypic plasticity of shoot-to-root ratio under variable light and nutrient availabilities. Evol Ecol 16:67-76

Baumert S, Khamzina A (2015) Allometric relations in Jatropha curcas production systems of Burkina Faso. J Arid Environ 120:95-104 
Chen H, Niklas KJ, Yang D, Sun S (2009) The effect of twig architecture and seed number on seed size variation in subtropical woody species. New Phytol 183:1212-1221

Chen H, Felker S, Sun S (2010) Allometry of within-fruit reproductive allocation in subtropical dicot woody species. Am J Bot 97:611-619

Cilas C, Bar-hen A, Montagnon C, Godin C (2006) Definition of architectural ideotypes for good yield capacity in Coffea canephora. Ann Bot 97:405-411

Costes E, Lauri P, Regnard J (2006) Analyzing fruit tree architecture: implications for tree management and fruit production. Hortic Rev 32:1-61

De Reffye P, Heuvelink E, Guo Y, Hu B-G, Zhang B-G (2009) Coupling process-based models and plant architectural models: a key issue for simulating crop production. In: Cao W, White J, Wang E (eds) Crop modeling and decision support. Springer, Berlin Heidelberg, pp 130-147

Divakara BN, Upadhyaya HD, Wani SP, Gowda C, Laxmipathi L (2010) Biology and genetic improvement of Jatropha curcas L.: a review. Appl Energy 87:732-742

Duursma RA, Mäkelä A (2007) Summary models for light interception and light-use efficiency of non-homogeneous canopies. Tree Physiol 27:859-870

Edrisi SA, Dubey RK, Tripathi V, Bakshi M, Srivastava P, Jamil S, Singh HB, Singh N, Abhilash PC (2015) Jatropha curcas L.: a crucified plant waiting for resurgence. Renew Sustain Energy Rev 41:855-862

Esther AK, Adomako B (2010) Genetic and environmental correlations between bean yield and agronomic traits in Coffea canephora. J Plant Breed Crop Sci 2:64-72

Firdaus M, Husni M (2012) Planting Jatropha curcas on constrained land: emission and effects from land use change. Sci World J 2012:1-7

Fitter AH, Stickland TR, Harvey ML, Wilson GW (1991) Architectural analysis of plant root systems 1. Architectural correlates of exploitation efficiency. New Phytol 118:375-382

Ghezehei SB, Annandale JG, Everson CS (2009) Shoot allometry of Jatropha curcas. South For 71:279-286

Ghosh A, Chikara J, Chaudhary DR (2011) Diminution of economic yield as affected by pruning and chemical manipulation of Jatropha curcas L. Biomass Bioenergy 35:1021-1029

Gichimu B, Omondi C (2010) Morphological characterization of five newly developed lines of arabica coffee as compared to commercial cultivars in Kenya. Int J Plant Breed Genet 4:238-246

Grams TE, Andersen CP (2007) Competition for resources in trees: physiological versus morphological plasticity. In: Esser K, Löttge U, Beyschlag W, Murata J (eds) Progress in botany. Springer, Berlin Heidelberg, pp 356-381

Hairiah K, Dewi S, Agus F, Velarde SJ, Ekadinata A, Rahayu S, van Noordwijk M (2011) Measuring carbon stocks across land use systems: a manual. World Agroforestry CentreICRAF, South East Asia Regional Office, Bogor, pp 1-154

Hallé F, Oldeman RA, Tomlinson PB (1978) Tropical trees and forests: an architectural analysis. Springer-Verlag, New York, pp 1-441

Hasnam, Hartati RS (2006) The availability of improved population for Jatropha curcas L seed (in Indonesian). In: ICECRD (ed) Proceeding of status of cultivation technology for Jatropha curcas L in Indonesia. Indonesian Centre for Estate Crop Research and Development, Jakarta, April 11-12, pp 1-69

Krishnamurthy L, Zaman-Allah M, Marimuthu S, Wani SP, Kesava Rao AVR (2012) Root growth in jatropha and its implications for drought adaptation. Biomass Bioenergy 39:247-252

Kuyah S, Dietz J, Muthuri C, Jamnadass R, Mwangi P, Coe R, Neufeldt H (2012) Allometric equations for estimating biomass in agricultural landscapes: II. belowground biomass. Agric Ecosyst Environ 158:225-234

Lacointe A (2000) Carbon allocation among tree organs: a review of basic processes and representation in functionalstructural tree models. Ann For Sci 57:521-533

Loague K, Green RE (1991) Statistical and graphical methods for evaluating solute transport models: overview and application. J Contam Hydrol 7:51-73

MacFarlane D, Kuyah S, Mulia R, Dietz J, Muthuri C, Noordwijk M (2014) Evaluating a non-destructive method for calibrating tree biomass equations derived from tree branching architecture. Trees 28:807-817

Mäkelä A (1986) Implications of the pipe model theory on dry matter partitioning and height growth in trees. J Theor Biol 123:103-120

Mäkelä A (2002) Derivation of stem taper from the pipe theory in a carbon balance framework. Tree Physiol 22:891-905

Mäkelä A, Albrektson A (1992) An analysis of the relationship between foliage biomass and crown surface area in Pinus sylvestris in Sweden. Scand J For Res 7:297-307

Mäkelä A, Valentine HT (2006) Crown ratio influences allometric scaling in trees. Ecology 87:2967-2972

Makungwa S, Chittock A, Skole D, Kanyama-Phiri G, Woodhouse I (2013) Allometry for biomass estimation in jatropha trees planted as boundary hedge in farmers' fields. Forests 4:218-233

Martin NA, Chappelka AH, Loewenstein EF, Keever GJ, Somers G (2012) Predictive open-grown crown width equations for three oak species planted in a southern urban locale. Arboric Urban For 38:58-63

Mokany K, Raison RJ, Prokushkin AS (2006) Critical analysis of root: shoot ratios in terrestrial biomes. Glob Change Biol 12:84-96

Mujumdar AM, Upadhye AS, Misar AV (2000) Studies on antidiarrhoeal activity of Jatropha curcas root extract in albino mice. J Ethnopharmacol 70:183-187

Mulia R, Dupraz C, van Noordwijk M (2010) Reconciling root plasticity and architectural ground rules in tree root growth models with voxel automata. Plant Soil 337:77-92

Negussie A, Achten WMJ, Verboven HAF, Hermy M, Muys B (2014) Floral display and effects of natural and artificial pollination on fruiting and seed yield of the tropical biofuel crop Jatropha curcas L. GCB Bioenergy 6:210-218

Niklas KJ (1993) The allometry of plant reproductive biomass and stem diameter. Am J Bot 80:461-467

Pompelli MF, Antunes WC, Ferreira DTRG, Cavalcante PGS, Wanderley-Filho HCL, Endres L (2012) Allometric models for non-destructive leaf area estimation of Jatropha curcas. Biomass Bioenergy 36:77-85

Prusinkiewicz P (2004) Modeling plant growth and development. Curr Opin Plant Biol 7:79-83

Rao GR, Prasad JVNS, Reddy PS, Kumar PS (2013) Carbon sequestration potential of Jatropha curcas in semiarid 
regions of southern India. In: Kumar S, Tyagi SK (eds) Recent advances in bioenergy research. SSS-NIRE, Punjab, pp 275-283

Reubens B, Achten WMJ, Maes WH, Danjon F, Aerts R, Poesen J, Muys B (2011) More than biofuel? Jatropha curcas root system symmetry and potential for soil erosion control. J Arid Environ 75:201-205

Salas E, Ozier-Lafontaine H, Nygren P (2004) A fractal root model applied for estimating the root biomass and architecture in two tropical legume tree species. Ann For Sci 61:337-345

Santos Martin F, Navarro-Cerrillo R, Mulia R, van Noordwijk M (2010) Allometric equations based on a fractal branching model for estimating aboveground biomass of four native tree species in the Philippines. Agrofor Syst 78:193-202

Scheffer M, Vergnon R, Cornelissen JHC, Hantson S, Holmgren M, van Nes EH, Xu C (2014) Why trees and shrubs but rarely trubs? Trends Ecol Evol 29:433-434

Smith DM (2001) Estimation of tree root lengths using fractal branching rules: a comparison with soil coring for Grevillea robusta. Plant Soil 229:295-304

Sunil N, Kumar V, Sujatha M, Rajeswara Rao G, Varaprasad KS (2013) Minimal descriptors for characterization and evaluation of Jatropha curcas L. germplasm for utilization in crop improvement. Biomass Bioenergy 48:239-249

Taub DR, Goldberg D (1996) Root system topology of plants from habitats differing in soil resource availability. Funct Ecol 10:258-264

Tjeuw J, Slingerland M, Giller K (2015) Relationships among Jatropha curcas seed yield and vegetative plant components under different management and cropping systems in Indonesia. Biomass Bioenergy 80:128-139

Valdés-Rodríguez OA, Sánchez-Sánchez O, Pérez-Vázquez A, Caplan JS, Danjon F (2013) Jatropha curcas L. root structure and growth in diverse soils. Sci World J 2013:1-9

van der Vossen, Herbert AM (1985) Coffee selection and breeding. In: Clifford MN, Willson KC (eds) Coffee. Springer, New York, pp 48-96

van Noordwijk M, Mulia R (2002) Functional branch analysis as tool for fractal scaling above- and belowground trees for their additive and non-additive properties. Ecol Model 149:41-51

van Noordwijk M, Purnomosidhi P (1995) Root architecture in relation to tree-soil-crop interactions and shoot pruning in agroforestry. In: Sinclair F (ed) Agroforestry: science, policy and practice. Springer, Netherlands, pp 161-173

van Noordwijk M, Spek L, Willigen P (1994) Proximal root diameter as predictor of total root size for fractal branching models: II numerical model. Plant Soil 164:107-117

Vos J, Evers JB, Buck-Sorlin GH, Andrieu B, Chelle M, de Visser PHB (2010) Functional-structural plant modelling: a new versatile tool in crop science. J Exp Bot 61:2101-2115

Wani SP, Chander G, Sahrawat KL, Srinivasa Rao C, Raghvendra G, Susanna P, Pavani M (2012) Carbon sequestration and land rehabilitation through Jatropha curcas (L.) plantation in degraded lands. Agric Ecosyst Environ 161:112-120

Westoby M, Wright IJ (2003) The leaf size-twig size spectrum and its relationship to other important spectra of variation among species. Oecologia 135:621-628 